FLORA

\section{Guide to Guatemala}

THE plant in the picture is one of the rarities described in the latest instalment of the Flora of Guatemala (Fieldiana: Botany, 24; 1969). It is the shrub Plocosperma buxifolium and is rare enough to have been collected only a few times in this part of Central America. It has colourful petals, described by the author, Dorothy N. Gibson, as blue-violet to purplish magenta. In the diagram, $A$ shows a fruiting branch, half natural size; $B$ is the flower, twice natural size, and $C$ shows the corolla, opened to reveal the stamens and pistil.

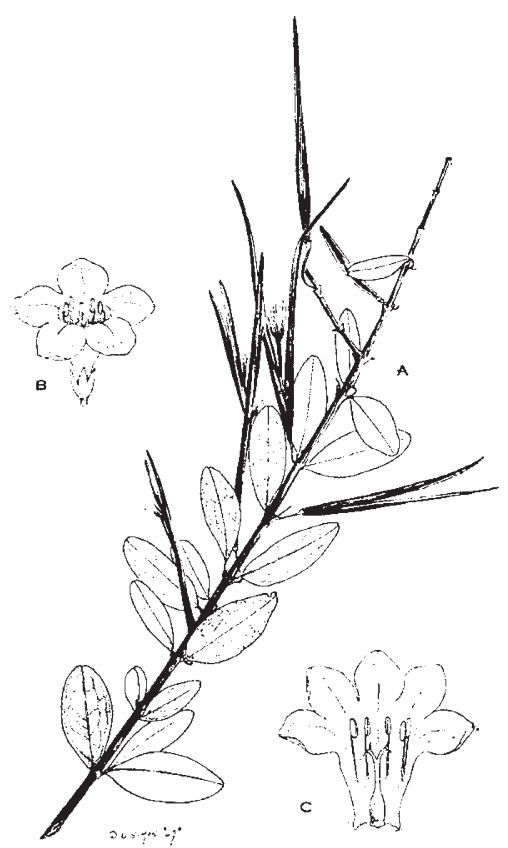

Plocosperma buxifolium belongs to the Loganaceae, one of six families dealt with in this volume. The other families (described by Paul C. Standley and Louis O. Williams) are the Oleaceae, which contains many ornamental plants as well as the familiar olive; the Gentianaceae, otherwise known as the gentians; the Apocynaceae - well represented in Guatemala - and the Asclepiadaceae, the members of which produce some seed pods that are used as a vegetable in Central America.

\section{PROTEIN SYNTHESIS}

\section{More about Initiation}

\section{from our Cell Biology Correspondent}

THE printing strike which prevented the publication of the Proceedings of the US National Academy of Sciences for a couple of months was as much a relief to students of molecular biology as it was a headache to competitors for rapid publication. The strike, of course, has long since been settled, the backlog seems to have been worked off and things are back to normal. There is once again the monthly flood of progress reports from groups working on protein synthesis, for example. In the latest issue, Lucas-Lenard and Haenni $(63,93 ; 1969)$ report that $t$ RNA molecules are released from a growing polypeptide chain during translocation as the peptidyl-tRNA is moved from the aminoacyl$t$ RNA acceptor site to the peptidyl site in the ribosome. Using acetylphenylalanyl-tRNA as an initiator, with the $t$ RNA part labelled with tritium, they assayed for the release of the labelled $t$ RNA during the synthesis of polyphenylalanine in a cell-free system programmed with poly.U. Release of the $t$ RNA is apparently dependent on the presence of the translocation factor $G$ and GTP. The $t$ RNA is not displaced during synthesis of the peptide bond but only as the dipeptidyl$t$ RNA moves from the acceptor site to the peptidyl site in the ribosome.

In the same issue of the Proceedings of the US National Academy of Sciences (page 99), Ochoa's group reports that GTP somehow protects the sulphydryl groups of the initiation factor $\mathrm{F}_{2}$ and allows it to remain active in promoting the binding of fMet-tRNA s $_{\text {s }}$ ribosomes under the influence of messenger RNA at initiation of protein synthesis, even in the presence of sulphydryl group blocking agents. The GTP forms a complex with $\mathrm{F}_{2}$ and presumably, as a result of either steric hindrance or some conformational change, this keeps intact the crucial SH groups; beyond that, however, the experiments throw no light on how $\mathbf{F}_{2}$ functions during initiation.

Despite much effort, little is known of the process of chain initiation in mammalian cells, and work has been held back by the lack of a cell-free system that will continue protein synthesis for more than a few minutes. Fuhr, London and Grayzel (ibid., 129), however, have rediscovered a soluble factor which stimulates protein synthesis, apparently by promoting initiation, in a rabbit reticulocyte system making globin. The factor is identical with, or very similar to, that described by Miller and Schweet in 1968, except that it is not bound to ribosomes but, rather, isolated from a supernatant fraction. The factor restores the ability of the cell-free system to incorporate valine at the $N$ terminus, and results of experiments to test whether it functions like one of the three initiation factors in $E$. coli are awaited with interest

In the latest issue of the Journal of Molecular Biology (43, 273; 1969), Rudland and Dube describe experiments in which they have investigated the $t$ RNA binding sites of the $30 S$ ribosomal subunit using a nonadecanucleotide fragment isolated from the initiator formylmethionine- $t \mathrm{RNA}$, and comprising the anticodon loop with the CAU anticodon intact. This fragment binds to the $30 \mathrm{~S}$ ribosome programmed with the initiator codons AUG and GUG in a fashion analogous to the intact $f M e t-t \mathrm{RNA}_{\mathrm{p}}$ but neither initiation factors nor GTP are required. The fragment competes with the intact $\mathrm{fMet}_{\mathrm{A}} \mathrm{RNA} \mathrm{A}_{\mathrm{p}}$ which indicates that they are both binding at the same site. But it does not compete for the site to which Met-tRNA $m$ and the other aminoacyl $t$ RNAs bind. Apparently the anticodon itself contains all the information necessary for decoding the initiator codons. The initiation factors must somehow interact with some other part of the fMet- $t$ RNAp molecule and allow it, rather than any other aminoacyl$t$ RNAs, to bind to the initiator site in the ribosome. It seems likely that in vitro the only stable binding site on the $30 S$ ribosome is that normally occupied by the initiator $t$ RNA. A stable binding site for all the other aminoacyl- $t$ RNAs is probably induced by the addition of a $50 S$ ribosome to the $30 S$ initiation complex. 